spark-line radiation does not bring about the emission of the yellow $D$ lines from sodium vapour. Work is in progress to develop the ideas expressed above. J. C. MCLennan,

The Physical Laboratory, RICHARD RUEDY.

University of Toronto, Feb. 7.

\section{The Sligo Artefacts.}

A LeTter in NATURE of Jan. 28 definitely establishes the human origin of the Sligo flakes, but the last sentence of the letter seems to suggest some mystery concerning their cultural age. In view of this it may not be superfluous to refer to the accompanying photograph (Fig. 1) which Mr. A. W. Stelfox has kindly lent us. The photograph (Fig. 1) was taken by Mr. R. W. Welch and shows a primitive limestone anchor similar to many that are still manufactured and used by the fishermen on the west coast of Galway. These anchors are made near the coast, and the resulting flakes are left lying about along

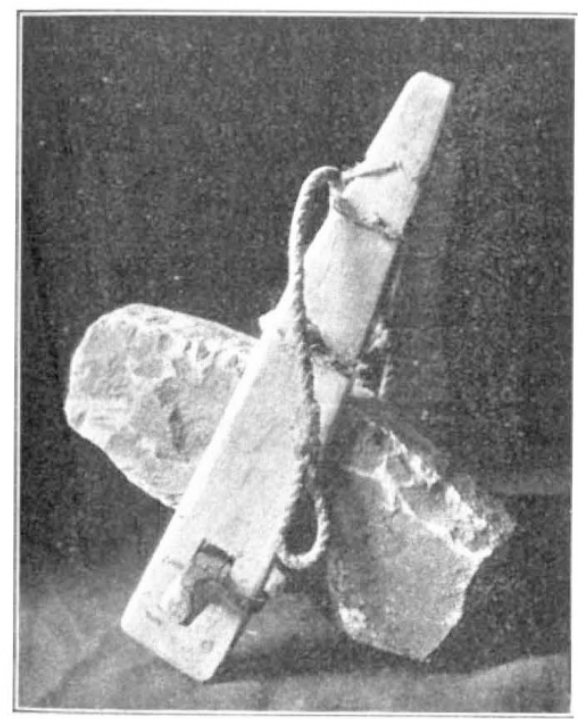

FIG. 1.-Primitive anchor, a heavy stone in wooden clamp, still used by Aran Islanders, west coast of Galway.

with larger discarded stones, all showing traces of their undoubted 'humanity.' Although no such anchors are now made at Rosses Point, it is highly probable, if not certain, that such stone anchors were made there, and also at many other parts of the Irish coasts one or two hundred years ago. In all probability the present beach on which the Sligo specimens were found was not in existence even a thousand years ago, so the possibility of the Sligo flakes being debris from primitive stone anchors should be taken into consideration when attempting to fix their cultural age.

These facts are no doubt known to the five signatories of the letter referred to, yet we think it worth while to place on record any evidence which might assist in the elucidation of the cultural age of the artefacts in question.

College of Technology, Manchester, Mar. 1

\section{S. PaLmer. \\ J. WILFRID JACKSON. \\ W. O'B. Pierce.}

No. 3048, VoL. 121]

\section{Factors which determine the Occurrence of the Green Ray.}

THE recent discussion of the green ray which has been appearing in NATURE prompts me to put on record a new theory of the phenomenon which occurred to me several years ago, but which I have refrained from publishing in the hope of securing proof. First let me say most emphatically that the phenomenon is real and not an illusion or after-image. No person trained in the observation of optical effects, both real and subjective, who has seen the phenomenon at its best, will have any doubt about its reality. There is also no question in my mind but that the usual explanation (atmospheric dispersion) is quite correct. The main question to answer is, Why is it seen so seldom, even under conditions which appear to be the most favourable?

I have crossed the ocean some thirty times and have looked for the 'ray' at every favourable opportunity, by which I mean clear sky, no haze or clouds on the horizon at sunset, and a calm sea, and yet I have observed it on only three or four occasions, and only once when it was really striking. This occasion was on an eastward trip of the Homeric, sailing from New York on June 6, 1925. The colour of the vanishing edge of the sun at sunset was a vivid emerald green, about the colour of a railroad signal light. On other occasions on which I have observed evidence of the phenomenon, the colour change was from red or orange to lemon yellow.

It seems possible that the determining factor is the relative temperature of the air and the ocean. Warm water and cool air would flatten the trajectory of the light rays, and cause the sun to set abnormally early. This is the type of refraction in cases of desert mirage, in which case the curvature of the rays is reversed. With cold water and warm air, on the contrary, the normal gradient of refractive index would be increased, the curvature of the rays augmented, and sunset would be delayed, giving a greater opportunity for atmospheric dispersion to come into play.

Through the courtesy of Capt. Parker, of the Homeric, I have been furnished with data regarding the air and water temperatures on this trip. On the day on which we observed the ray, the temperatures of air and water were practically the same at sunset. On the other three favourable evenings, on which we failed to see any trace of the phenomenon, the ocean was from twelve to fourteen degrees warmer than the air at sunset. I hope that this note may prompt future observers of the green ray to secure data on the air and water temperature, both for occasions on which it is not seen, as well as those on which it is well marked.

\section{Johns Hopkins University, Baltimore.}

\section{A New Type of Secondary Radiation.}

IF we assume that the $\mathrm{X}$-ray scattering of the ' unmodified' type observed by Prof. Compton corresponds to the normal or average state of the atoms and molecules, while the 'modified' scattering of altered wave-length corresponds to their fluctuations from that state, it would follow that we should expect also in the case of ordinary light two types of scattering, one determined by the normal optical properties of the atoms or molecules, and another representing the effect of their fluctuations from their normal state. It accordingly becomes necessary to test. whether this is actually the case. The experiments we have made have confirmed this anticipation, and 